\title{
REFLEXÃO TEÓRICA SOBRE AS CONTRIBUIÇÕES DA OBRA DE PAULO FREIRE PARA A EDUCAÇÃO ESPECIAL
}

\author{
REFLEXIÓN TEÓRICA SOBRE LAS CONTRIBUCIONES DE LA OBRA DE PAULO \\ FREIRE A LA EDUCACIÓN ESPECIAL
}

\author{
THEORETICAL REFLECTION ON THE CONTRIBUTIONS OF PAULO FREIRE'S \\ WORK TO SPECIAL EDUCATION
}

\author{
Silvia Cristina Pereira dos SANTOS ${ }^{1}$ \\ Geilsa Soraia Cavalcanti VALENTE ${ }^{2}$ \\ Elaine Antunes CORTEZ ${ }^{3}$ \\ Suellen Gomes Barbosa ASSAD ${ }^{4}$ \\ Renata Souza VOGAS ${ }^{5}$
}

RESUMO: Objetivo: refletir sobre as contribuições da obra de Paulo Freire para a educação especial. Método: trata-se de uma reflexão teórica, de abordagem qualitativa, fundamentada nos conceitos tratados por Paulo Freire na sua obra traçando um paralelo com a educação especial de jovens e adultos. Resultados e Discussão: a partir do conhecimento oferecido pela obra de Freire, num processo reflexivo sobre a prática, emergiram possibilidades de se trabalhar as áreas potenciais dos educandos, de forma ética, apostando na construção mais horizontalizada entre docente e discente, objetivando ultrapassar suas limitações. Considerações Finais: depreende-se a premente necessidade de formação permanente dos docentes que atuam na educação especial, no intuito de desenvolver competências e habilidades, como subsídios para a elaboração de estratégias educacionais que impulsionem uma educação libertadora, contribuindo assim para a construção de outro modo de vida mais justo na Educação Especial.

PALAVRAS-CHAVE: Pessoas com deficiência. Aprendizagem. Docente. Educação especial.

\footnotetext{
${ }^{1}$ Universidade Federal Fluminense (UFF), Niterói - RJ - Brasil. Doutoranda do Programa Acadêmico em Ciências do Cuidado em Saúde. ORCID: https://orcid.org/0000-0002-1612-3334. E-mail: silviacps56@gmail.com

${ }^{2}$ Universidade Federal Fluminense (UFF), Niterói - RJ - Brasil. Professora Associada do Departamento de Fundamentos de Enfermagem e membro do Corpo Permanente do Programa Acadêmico em Ciências do Cuidado em Saúde e do Mestrado Profissional em Ensino na Saúde. Doutorado em Enfermagem (UFRJ). ORCID: https://orcid.org/0000-0003-4488-4912. E-mail: geilsavalente@gmail.com

${ }^{3}$ Universidade Federal Fluminense (UFF), Niterói - RJ - Brasil. Professora e Coordenadora do Mestrado Profissional em Ensino na Saúde. Doutorado em Enfermagem (UFRJ). ORCID: https://orcid.org/0000-00033912-9648. E-mail: nanicortez@hotmail.com

${ }^{4}$ Universidade Federal Fluminense (UFF), Niterói - RJ - Brasil. Doutoranda do Programa Acadêmico em Ciências do Cuidado em Saúde. ORCID: https://orcid.org/0000-0002-4911-3837. E-mail: suellengomesbarbosa@gmail.com

${ }^{5}$ Universidade do Grande Rio (UNIGRANRIO), Duque de Caxias - RJ - Brasil. Mestranda do Mestrado Profissional em Ensino das Ciências na Educação Básica. ORCID: https://orcid.org/0000-0002-4911-3837. Email: renatavogas@bol.com.br
} 
RESUMEN: Objetivo: reflexionar sobre las contribuciones del trabajo de Paulo Freire a la educación especial. Método: se trata de una reflexión teórica, con enfoque cualitativo, basada en los conceptos tratados por Paulo Freire en su obra, haciendo un paralelo con la educación especial de jóvenes y adultos. Resultados y Discusión: a partir del conocimiento que ofrece el trabajo de Freire, en un proceso reflexivo sobre la práctica, surgieron posibilidades de trabajar las áreas potenciales de los estudiantes, de manera ética, apostando por una construcción más horizontal entre docente y alumno, con el objetivo de superar sus limitaciones. Consideraciones finales: existe una urgente necesidad de formación permanente de los docentes que laboran en educación especial, con el fin de desarrollar habilidades y habilidades, como subsidios para el desarrollo de estrategias educativas que promuevan una educación libertadora, contribuyendo así a la construcción de otra más justa en Educación Especial.

PALABRAS CLAVE: Personas con discapacidad. Aprendizaje. Docente. Educación especial.

ABSTRACT: Objective: reflect on the contributions of Paulo Freire's work to special education. Method: it is a theoretical reflection, with a qualitative approach, based on the concepts treated by Paulo Freire in his work, drawing a parallel whith the special education of young people and adults. Results and Discussion: from the knowledge offered by Freire's work, in a reflective process about the practice, possibilities emerged to work the potencial areas of the students, in an ethical way, betting on a more horizontal construction between teacher and student, aiming to overcome their limitations. Final Considerations: there is an urgent need for permanent training of teachers working in special education, to develop skills and abilities, as subsidies for the development of educational strategies that promote a liberating education, thus contributing to the construction of another way of life, fair in Special Education.

KEYWORDS: People with disabilities. Learning. Teacher. Special education.

\section{Introdução}

Paulo Freire foi, sem dúvida alguma, o teórico que marcou a história da educação, propondo uma vivência humanizada, advinda das experiências do sujeito, mediatizada pelo mundo e pautada na prática da liberdade. $O$ autor traz em sua práxis libertadora a importância da educação no processo de transformação, quando afirma que “[...] a práxis é a reflexão e ação dos homens sobre o mundo para transformá-lo. Sem ela, é impossível a superação da contradição opressor-oprimido" (FREIRE, 2020, p. 52).

A pedagogia do oprimido se revela como a pedagogia dos homens, empenhando-se na luta por sua libertação, tomando consciência crítica de sua opressão. Desse modo, a pedagogia do oprimido, como pedagogia humanista e libertadora, terá dois momentos distintos. O primeiro encontra-se o período em que os oprimidos vão desvelando o mundo da 
opressão e vão comprometendo-se, na práxis, com a sua transformação. Já no segundo momento, a partir da transformação da realidade opressora, esta pedagogia deixa de ser do oprimido e passa a ser a pedagogia dos homens, em processo de permanente libertação (FREIRE, 2020).

Ao aproximar o pensamento de Paulo Freire (2020) com a realidade da educação especial, chama atenção a reflexão proposta pelo autor a respeito da autodesvalia, sendo uma característica dos oprimidos, o que se coloca como resultado da introjeção que fazem eles da visão que deles têm os opressores. Assim, acredita-se que de tanto ouvirem de si mesmos que são incapazes, que não sabem nada, que nada aprendem, que são "enfermos", que não produzem, em virtude de tudo isto, as pessoas com deficiência, bem como seus familiares, podem terminar por se convencer de sua incapacidade, gerando uma autodesvalia, que lhes bloqueia as perspectivas de futuro.

Nesse contexto, observa-se que, historicamente, a nossa educação constituiu-se de forma a separar os educandos em normais e anormais; fortes e fracos, dentre outros adjetivos. Diante dessa forma de pensar a educação, muitas crianças, jovens e adultos estiveram longe das escolas públicas, não apenas crianças com deficiências (KASSAR, 2011). Assim, considera-se a situação de opressão que essas pessoas viveram ao longo da história, sem ao menos serem vistos e ouvidos, como um fator gerador de exclusão.

Após inúmeros movimentos e construções de documentos com vistas à implantação de políticas públicas, tais como a participação do Brasil na Conferência Mundial sobre Educação para Todos, em Jomtien, na Tailândia, coube ao país, como signatário da Declaração Mundial sobre Educação para Todos, o compromisso de assegurar a universalização do direito à Educação (UNESCO, 1990).

No que tange à Educação Especial, a Declaração de Salamanca enfatiza que:

O direito de cada criança a educação é proclamado na Declaração Universal de Direitos Humanos e foi fortemente reconfirmado pela Declaração Mundial sobre Educação para Todos. Qualquer pessoa portadora de deficiência tem o direito de expressar seus desejos com relação à sua educação, tanto quanto estes possam ser realizados. Pois possuem o direito inerente de serem consultados sobre a forma de educação mais apropriada às necessidades, circunstâncias e aspirações (DECLARAÇÃO DE SALAMANCA, 1994, p. 3).

Sob o impacto desses documentos e dentro de um conjunto de políticas sociais, um discurso de "educação inclusiva" toma corpo no país, de modo que profissionais que atuavam na Educação Especial passam, pouco a pouco, a utilizar o termo "inclusão" no lugar 
de "integração" (KASSAR, 2011). E assim, no Brasil, "nasce” a Lei Brasileira de Inclusão (13146/15), fruto de muitas lutas, que em seu artigo 27 traz a seguinte afirmativa:

A educação constitui direito da pessoa com deficiência, assegurado no sistema educacional inclusivo em todos os níveis e aprendizado ao longo de toda a vida, de forma a alcançar o máximo desenvolvimento possível de seus talentos e habilidades físicas, sensoriais, intelectuais e sociais, segundo suas características, interesses e necessidades de aprendizagem (BRASIL, 2015).

É possível verificar neste cenário que a implementação das políticas voltadas para a inclusão não foi dissociada de conflitos e tensões historicamente vividos até aqui. Muitos foram os desafios enfrentados pelo público da Educação Especial, especificamente, estudantes com Deficiência, Transtornos Globais do Desenvolvimento e Superdotação e/ou Altas Habilidades, conforme prevê a Lei Brasileira de Inclusão (2015), que dispõe sobre os direitos desses educandos, garantindo que estes tenham possibilidades não só de acesso e participação na aprendizagem, mas para além disto. Nesse prisma, segundo Polo (2019), que sejam capazes de desenvolver suas habilidades e competências para uma vida plena, não numa "mera repetição de conteúdos", aplicados de forma verticalizada, numa prática tradicional.

Diante do exposto, em concordância com a história de segregação, separação e luta pela educação para todos, a obra Freiriana aponta que, para alcançar o máximo desenvolvimento possível do estudante é preciso compreender a partir da dialogicidade a realidade deste aluno, seus anseios, seus desejos, suas potencialidades. Freire (2020, p. 72) defende que "[...] o diálogo crítico e libertador, por isto mesmo que supõe a ação, tem de ser feito com os oprimidos, qualquer que seja o grau que esteja a luta por sua libertação". A partir dessa afirmativa, tem-se a perspectiva da educação construída com a pessoa, e não para a pessoa.

Marques (2007), ao se referir à obra freiriana para a inclusão, aponta que o diálogo não consiste apenas numa troca de informações entre indivíduos. A implicação ativa de cada um faz com que tanto o diálogo quanto os sujeitos nele envolvido estejam em permanente transformação. Trata-se de instrumento de transformação das pessoas e do mundo.

Refletindo sob a ótica do docente na relação com os estudantes, observando o processo permanente pelo qual a educação vive seus processos de mudanças, a própria Lei 13.146/2015 aponta à respeito da formação do professor:

$\mathrm{X}$ - adoção de práticas pedagógicas inclusivas pelos programas de formação inicial e continuada de professores e oferta de formação continuada para o 
atendimento educacional especializado; XI - formação e disponibilização de professores para o atendimento educacional especializado, de tradutores e intérpretes de Libras, de guias intérpretes e de profissionais de apoio (BRASIL, 2015).

Desse modo, apesar do professor vir com sua formação inicial, a lei aponta a importância do investimento na formação continuada do educador, uma vez que a cada novo tempo, novos desafios se colocam à prática docente, e a inclusão também se faz no processo diário, podendo-se inferir, de acordo com Freire (2011), que à medida que o professor permanece refletindo criticamente a prática docente, torna-se capaz de melhorar a próxima prática.

Assim sendo, segundo Polo (2019), a meta é a idealização do espaço escolar, com investimento na preparação de educadoras e educadores para a reconstrução do conhecimento significativo, demolindo barreiras estruturais e um ensino apenas propedêutico, na defesa para a solidez do fazer pedagógico e novos espaços educativos dinamizadores, na revolução do pensar e agir dos estudantes, por meio de suas competências e acesso ao nível mais elevado do ensino.

Desse modo, visando à lógica da construção de uma prática pedagógica inclusiva, na educação especial, aberta à dialogicidade e valorização das potencialidades do educando, o presente estudo tem como objetivo refletir acerca das contribuições da obra de Paulo Freire para a educação especial.

\section{Metodologia}

Trata-se de um artigo de reflexão teórica, de abordagem qualitativa, fundamentado nos conceitos tratados por Paulo Freire na sua obra, traçando um paralelo com a educação especial de jovens e adultos.

A partir da leitura acerca da percepção de pensadores sobre a obra Pedagogia do Oprimido realizou-se uma análise reflexiva, aproximando as ideias de Paulo Freire na referida obra com a educação especial e suas nuances. Para tanto, desenvolveu-se a discussão dos resultados em momentos sequenciados, tomando como base o percurso do autor no intuito de favorecer a reflexão sobre esta prática. 


\section{Resultados e Discussão}

\section{O percurso de vida retratado em suas obras}

As obras de Freire contribuíram para a construção da teoria ético-crítico-política da educação, que possibilita a conscientização com o objetivo de formar cidadãos da práxis, a partir de uma pedagogia crítico-reflexiva. Sua obra é resultado de suas experiências como sujeito, pois Freire observava e vivenciava cada detalhe como fonte para aprendizagem.

Paulo Reglus Neves Freire nasceu em Recife, no dia 19 de setembro de 1921. Dedicou seu primeiro livro: Educação como prática da liberdade, aos seus pais: Joaquim Temístocles e sua mãe, Edeltrudes Neves Freire. O autor dizia que foi com eles que aprendeu o diálogo que mantinha com o mundo, com os homens, com Deus e com sua mulher e filhos (BARRETO, 1998).

Ao relembrar a infância, Freire, por inúmeras vezes, em seus escritos ou conferências, se referia a esta fase com lembranças mescladas de saudades e emoções. Tratava a sua casa e todo o quintal rodeado de árvores como o seu primeiro mundo. Ainda na representação do local em que morava, Freire falava sobre a alfabetização, lembrando que foi o chão do quintal de sua casa o seu quadro-negro, e pedaços de madeira o seu giz (BARRETO, 1998). Paulo Freire sempre demonstrou um olhar especial para aquilo que era simples, mas era justamente no simples que ele buscava a transformação e sempre a partir da reflexão, de um saber permanente, em movimento.

Paulo Freire ingressou na Faculdade de Direito do Recife e mesmo depois de formado continuou como professor de português no Colégio Oswaldo Cruz (BARRETO, 1998; GADOTTI et al., 1996). Paulo Freire só teve uma experiência como advogado e acaba abandonando a profissão. Logo depois ele ingressa no Serviço Social da Industria (SESI), lugar em que se dedicou por longos dez anos, considerado por ele como "tempo fundante", porque aqui iniciou sua compreensão a respeito do processo de aprendizagem dos grupos populares. Após sua saída do SESI, em 1959, Freire se torna professor de Filosofia da Educação no curso de Professorado de Desenho da Escola de Belas Artes da Universidade Federal de Pernambuco (REIS, 2012).

Em 1960, Miguel Arraes, prefeito da cidade de Recife, demonstrou interesse em ampliar os trabalhos de educação de crianças e adultos nas áreas da pobreza. E foi a partir daí que surgiu o convite para intelectuais, sindicalistas e o povo para o movimento de divulgação, surgindo o Movimento de Cultura Popular de Pernambuco (MCP). E Freire foi um dos intelectuais que participou do movimento. O MCP trabalhava não só com a alfabetização, mas 
com o teatro popular. Foi no MCP que o autor fez suas primeiras experiências no campo da alfabetização de adultos, considerado por ele como processo de conscientização (BARRETO, 1998; REIS 2012).

A partir daí Freire defendia uma pedagogia democrática, que partia das ansiedades, dos desejos, dos sonhos, das carências das classes mais oprimidas e por isso sua prática provocou profunda raiva nas classes dominantes. O autor construiu um "método de alfabetização", realizado por meio de Círculos de Cultura e logo despertou grande interesse nacional e latino-americano. O processo de aprendizagem era construído a partir da realidade dos alunos, para gerar "palavras chave", que eram trabalhadas e que, potencialmente, conduziriam a uma ampliação da visão do mundo dos estudantes, podendo se constituir em processo conscientizador de sua condição de submissão e exploração, levando-os a estarem compromissados com a transformação da sociedade (FREIRE, 2020).

Era uma visão revolucionária de educação, em que Freire tecia as críticas à educação bancária e fazia nascer a educação crítica como prática da liberdade. Devido a suas ideias, e com o golpe militar de 1964, vieram as perseguições políticas: Paulo Freire foi acusado de agitador e levado para a prisão, onde passou 70 dias, considerado um subversivo internacional, traidor de Cristo e do povo brasileiro. Assim, ele ficou no asilo na Embaixada da Bolívia e em seguida deixou o país, se exilando no Chile por longos 16 anos, país que Freire considerou como lugar de consolidação do seu pensamento (BARRETO, 1998; GADOTTI et al., 1996).

\section{Pedagogia do Oprimido: Perspectiva de uma educação libertadora}

No tempo de exílio no Chile, longe da sua terra, Freire escreve um livro, Pedagogia do Oprimido, que mesmo construído em português, inicialmente foi entregue a uma editora norte-americana que o editou pela primeira vez, em inglês, no ano de 1970. Hoje, esta é obra clássica na educação e já foi traduzida em mais de 30 idiomas (BARRETO, 1998).

Com a Pedagogia do Oprimido, Paulo Freire revolucionou o sistema de ensino de adultos no mundo todo, criando um modelo pedagógico inovador ao apresentar uma proposta de educação crítico libertadora, voltada para o contexto sociocultural. Sua obra maior estabeleceu uma proposta de educação revolucionária, firmada em concepções que estruturam uma teoria educacional libertadora, preocupada com o ser humano, e, sobretudo, com os oprimidos do mundo. Embora na atualidade alguns ainda reduzam o pensamento de Paulo Freire somente a uma proposta de alfabetização de adultos, no final dos anos 1970 o autor já 
era reconhecido internacionalmente e estudado em diversas áreas do conhecimento (ABREU, 2019).

Segundo Freire (2020), o homem é entendido como ser inconcluso, consciente de sua inconclusão e seu processo permanente de ser mais. Ele sintetiza que essa é a nossa vocação, compreendida como desejo de liberdade e de justiça, pois implica em mudança de paradigmas, em que a educação se faz, refletindo e agindo de maneira consciente, na prática pedagógica cotidiana, para transformá-la. Eis uma análise complexa que requer o exercício do diálogo, da consciência da sua finitude e da mudança de si mesmo e do mundo. Além da questão política, adentramos na perspectiva ética da obra, a fim de elucidar a ética pedagógica em que o autor chama a atenção para aqueles que vivem na opressão, dominação e dependência. A ética se refere à indignação provocada por injustiças e modos de opressão.

Paulo Freire explica o termo oprimido, afirmando que o homem tem de transformar-se num sujeito da realidade histórica em que se insere, humanizando-se, lutando pela liberdade, pela desalienação e pela sua afirmação, enfrentando uma classe dominadora que pela opressão, exploração e injustiça tenta permanecer. A pedagogia do oprimido, humanista e libertadora, apresenta-se como uma pedagogia de lutas, num processo permanente pela libertação, por meio da reflexão sobre a opressão e suas causas, em busca de uma ação transformadora, denominada por práxis libertadora (FREIRE, 2020).

Pletsch (2020) propõe em seus escritos que as propostas educacionais para as pessoas com deficiência levem sempre em consideração as circunstâncias sociais e de existência destes sujeitos, para além das características que a deficiência lhes impõem. Não muito diferente do cenário de institucionalização da Educação Especial em solo brasileiro, as práticas educacionais ainda hoje funcionam, muitas vezes, como ações paralelas e desarticuladas do Ensino Regular Comum, onde sujeitos laudados beneficiam-se dos espaços escolares como meros locais de socialização e não como promotores de ações que os legitimem e favoreçam a construção de sua autonomia, de novas aprendizagens e habilidades.

Em outras palavras, penso que a educação inclusiva é um princípio que não deve ser aplicado e interpretado de forma homogênea sem considerar os contextos e as particularidades dos grupos envolvidos. Por exemplo, para o público da Educação Especial a educação inclusiva representou um avanço fundamental e necessário para conquistar direitos de acesso à escola comum regular, o que de maneira geral beneficiou a aprendizagem e o desenvolvimento da maioria dessa população (PLETSCH, 2020, p. 66).

Assim como se propõe nas políticas públicas que o direito à educação para pessoas com deficiência seja garantido por lei, refletindo e pensando com os estudantes com 
deficiência, a partir das suas possibilidades e seus anseios, e não interrompidos em progredirem, devido as suas limitações, Freire (2020) também aponta em seus escritos que só na convivência com os oprimidos se poderá compreender as suas formas de ser, de se comportar e de refletir sobre a estrutura da dominação. Para o autor, será por meio dessa aproximação, e a reflexão de como se percebem e quais os meios de enfrentarem a lógica opressora, que favorecerá o movimento libertador.

Nesse contexto, o autor defende que os homens se educam entre si, mediatizados pelo mundo, pela educação problematizadora, que exige a superação da contradição educador e educando e o diálogo, em que ambos se tornam sujeitos do processo e crescem juntos em liberdade, procurando o conhecimento verdadeiro e a cultura pela emersão das consciências para uma inserção crítica na realidade (FREIRE, 2020).

Para Pletsch (2020), a Educação Especial, modalidade de Ensino Transversal, que perpassa todos os níveis educacionais, deve ser entendida como um campo do conhecimento e não pode ser entendida sem considerar o caminho histórico que percorreu em diferentes áreas do saber e as interferências que sofreu por parte delas em seus fundamentos, atravessada, por exemplo, pelas contribuições da Medicina, da Psicologia, da Sociologia e da Pedagogia.

Assim sendo, a partir da problematização, e a importância da dialogicidade nas diferentes áreas, enquanto essência da educação como prática da liberdade, o autor explora o conceito de diálogo, visto como fenômeno humano, pois segundo Paulo Freire (2020), não há palavra verdadeira que não seja práxis, enquanto ato de criação que procura a conquista do mundo para a libertação dos homens.

Daí advém a característica fundante da pedagogia da libertação popular: a dialogicidade da relação entre educador e educando, a qual implica na interação entre as pessoas. Ademais, a educação problematizadora é essencialmente reflexiva e dialógica, pois contrapõe a comunicação verticalizada e esvaziada de reflexão crítica como instrumento de domesticação do oprimido e preconizada pela educação bancária que, por sua vez, é antidialógica, alienante, transmissiva e domesticadora. Reconhecemos que a educação não pode ser concebida como transmissão de conhecimentos, visto que o diálogo representa a expressão da ação e da reflexão do direito de ser mais (CORRÊA, 2019).

Para Corrêa (2019), de fato, Freire enxergou com clareza que a dialogicidade é a essência da educação como prática da liberdade. Para ele, o fundamento do diálogo é o amor, concebido como dimensão política que implica em dialogar, conviver e respeitar o outro. Nesse sentido, o diálogo é utilizado para libertar os oprimidos, visto que as relações de respeito, conscientização e ética desafiam a ressignificação dos papéis entre educadores e 
educandos, e é justamente esse o diferencial para estabelecer uma prática social transformadora.

Notável pela sua importância mundial em diversas áreas, conforme Purcari (2019), os conceitos freirianos presentes na Pedagogia do Oprimido, durante o processo de libertação, nos revela uma relação teórico-prática, inovadora, da práxis educacional. Mediante a problematização da realidade do educando, uso de temáticas geradoras contextualizadas, realistas e diversificadas do currículo e do mundo, fundada na criatividade, no diálogo, reflexão e conscientização, possibilita uma educação com papel libertador na busca da humanização que tanto almejamos na educação especial.

\section{A educação como processo permanente de "ser mais"}

Freire desenvolveu um estilo de educação próprio, possível de ser utilizado para a aplicação no cotidiano da educação e de forma permanente. Como já dito anteriormente, Paulo Freire prioriza a ação humana com base na comunicação dialógica, sendo esta comunicação horizontal, onde os sujeitos sociais compartilham experiências na transformação e autotransformação.

Os pensamentos do autor surgem como um desafio para a educação pós-moderna, pois conforme já dizia o mesmo, "nem tudo está perdido", a partir de uma educação verdadeira vem a mudança da realidade, onde se cuidava fundamentalmente da relação baseada no ensino e aprendizagem em torno do educador, havendo cinco etapas a serem analisadas e processadas para atingir o sucesso, sendo elas o homem, metodologia, educação, processo de aprendizagem e educando. Por volta de todo esse processo, Paulo Freire vê a educação cheia de esperança, e logo não hesitou em chamá-la de Pedagogia da Esperança, já que ela pode transformar a realidade dependendo da maneira de como a aplicamos, de como nos posicionamos perante a educação, de como deixamos ser tocados por este processo, visto por Freire como algo tão vital (BRITO; SILVA; MONTENEGRO, 2012).

$\mathrm{Na}$ carta em que o teórico escreve sobre Educação Permanente e a Cidade Educativa, elucida-se a importância da educação e da formação, quando o educador em voga afirma:

A educação é permanente não porque certa linha ideológica ou certa posição política ou certo interesse econômico o exijam. A educação é permanente na razão, de um lado, da finitude do ser humano, de outro, da consciência que ele tem de sua finitude. Mais ainda, pelo fato de ao longo da história, ter incorporado à sua natureza e não saber que vivia, mas saber que sabia e,

RIAEE - Revista Ibero-Americana de Estudos em Educação, Araraquara, v. 16, n. 4, p. 2741-2759, out./dez. 2021. e-ISSN: 1982-5587 
assim, saber que podia saber mais. A educação e a formação permanente se juntam aí (FREIRE, 1992, p. 3).

Evidencia-se, desse modo, que a pedagogia crítica de Freire vislumbra uma educação de caráter ascendente, que coloca o estudante participante do processo como protagonista ativo, e considera suas experiências anteriores e o contexto sociocultural em que estão inseridos no processo ensino-aprendizagem, fazendo com que as temáticas abordadas sejam tratadas de modo a fazerem sentido para as pessoas envolvidas e tornarem-se possíveis de serem implementadas. Neste sentido, Português (2019) salienta que na práxis do olhar Freiriano, menosprezar a experiência do aprendente no repasse cognitivo é o mesmo que extinguir sua presença da vida. Quando o educador reconhece a realidade do aluno em seu território, maiores serão as chances de o conhecimento compartilhado vir a ser uma verdadeira ferramenta de transformação. Esse reconhecimento é via de mão dupla para sistematicamente rediscutir, reconversar e repactuar as questões magnas e abrir portais de novas percepções.

Freire (1979, p. 14) diz que "[...] a busca deve ser algo e deve traduzir-se em ser mais: é uma busca permanente de si mesmo [...]”. Deste modo, o que movimenta toda transformação nos serviços é na verdade a inquietação com o instituído, que de forma permanente, vai demandar novas estratégias em formular ações, integrando a escuta sensível ao processo de rupturas de paradigmas, considerando a educação como algo em movimento, o que leva ao processo reflexivo, e remete a uma ação que é o ato de buscar, buscar algo, por algum motivo, por alguma necessidade (SANTOS, 2015).

Desse modo, Freire (1979) apresenta a educação como um caráter permanente, pois para ele o saber se faz de forma constante, por isso, não há seres educados e não educados, estamos todos nos educando, e estabelece a reflexão como eixo norteador de todo trabalho, considerando que a formação parte da totalidade do sujeito e que nenhum conhecimento fica à margem. Assim, a consciência tanto da desumanização praticada pelo opressor, quanto da nossa incompletude enquanto seres humanos, é passo importante para a luta contra a dominação e opressão. Tal incompletude impõe aos atores sociais uma postura de eternos aprendizes (VITORINO, 2019).

Diante do pensamento reflexivo do autor, considera-se aqui que se faz necessário olhar para as pessoas com deficiência, investindo em suas potencialidades, desenvolvendo habilidades e competências, e não as reduzindo em suas limitações. A perspectiva que se tem, neste sentido, é, a partir do diálogo, construir caminhos possíveis de vivenciar novas trilhas, novas práticas, que sejam dentro e fora do espaço escolar. Não se deseja dessa forma falar das 
deficiências, e sim das potencialidades, justamente por se compreender o homem como sujeito inacabado, em pleno desenvolvimento.

O conceito de desenvolvimento humano adotado aqui se aproxima ao de desenvolvimento cultural, que, sob a perspectiva histórico-cultural, concebe o desenvolvimento dos sujeitos como um processo complexo de apropriação, por cada indivíduo em sua particularidade, dos bens culturais socialmente produzidos pela humanidade em cada momento histórico. Portanto o desenvolvimento humano é, ao mesmo tempo, um processo particular e coletivo/social, em que a aprendizagem impulsiona o desenvolvimento (KASSAR, 2016 apud PLETSCH, 2020, p. 63).

Levando em consideração uma política de educação inclusiva com uma proposta pautada no desenvolvimento integral dos sujeitos com deficiência, Pletsch (2020, p. 63) contribui com uma visão de inclusão educacional alicerçada nas convicções dos direitos humanos, onde os alunos com deficiência possam participar do seu processo de aprendizagem como protagonistas, aprendendo de modo significativo "[...] na convivência com a diversidade cultural, numa escola/universidade com todos e para todos".

Para Moura (2019), em sentido lato, o termo Pedagogia pode ser utilizado para referirse aos saberes constituintes do âmbito educacional, uma das formas de atuação humana. Em sentido estrito, remete à "arregimentação" e à organização dos aspectos a serem considerados no processo de construção do conhecimento, tanto para os responsáveis pelo processo de ensino, como para os que a esses confiam o processo de aprendizagem. Tal organização estaria assentada em dois pilares: que saberes privilegiar e como tais saberes poderão ser colocados a serviço dos processos de ensino e de aprendizagem.

Pensando na educação que nasce de um processo de troca, de construção e de comunhão, Freire (2011, p. 24) afirma que “[...] ensinar não é transferir conhecimento, mas criar as possibilidades para a sua produção ou a sua construção". Partindo deste princípio, a construção é dialógica entre educador e educando, observando as possibilidades existentes no território em que vivem, com características territoriais, aspectos sociais e culturais específicos, e é de extrema importância considerar tais especificidades no processo de construção do conhecimento, principalmente para o estudante com deficiência, das leves às mais severas, com as possibilidades e as condições de acessibilidade oferecidas pela escola e pela sociedade em geral, muitas vezes enraizadas por espaços e práticas segregadoras, como evidencia Pletsch (2020).

Diante do exposto quanto ao homem como ser social, cultural, regional e histórico, tem-se o pensamento do autor, em sua obra Pedagogia da Autonomia, ao afirmar que o 
educador precisa se mover com clareza na sua prática, conhecendo as diferentes dimensões que caracterizam a essência da prática. Tal atitude tornará este profissional mais seguro no seu desempenho (FREIRE, 2011). Portanto, para um olhar tão amplo, faz-se necessário ser um Educador. A pergunta que se coloca em questão é: de que prática docente estamos falando?

Sobre este aspecto, refletindo sobre a prática docente humanizadora, Moura (2019) refere à importância de se conhecer a si mesmo, e isso se daria também por meio da palavra, poderia desencadear um movimento em direção às mudanças no mundo pela palavra-ação, que permite a instauração do resgate da intersubjetividade, essencial para a humanização. Eis o contraponto entre a educação bancária e a educação problematizadora: a consciência como centro de valoração do mundo e o papel da palavra na construção dessa valoração, percurso no qual a intersubjetividade se sobrepõe à alteridade e à subjetividade. A palavra é, então, o combustível da consciência; não a palavra vazia, mas a "palavramundo", que confere à consciência o status de força motriz das relações entre os sujeitos, entre eles e a realidade. Uma pedagogia em que a palavra é pronunciada para mudar o mundo, não para confirmá-lo.

\section{A prática docente: um caminho reflexivo e a ação dialógica}

Freire destacava a importância da relação entre educadores e educandos, pautada pelo diálogo político-pedagógico, na apropriação crítica do conhecimento. Por isso, o autor aponta que é legítima a reflexão a respeito da formação docente e sua prática educativo-crítica (FREIRE, 2011). Nesta relação educador-educando, o autor aponta a formação que se constrói em ambos os lados, quando afirma que:

É preciso que, pelo contrário, desde os começos do processo, vá ficando cada vez mais claro que, embora diferentes entre si, quem forma se forma e re-forma ao formar e quem é formado forma-se e forma ao ser formado. É neste sentido que ensinar não é transferir conhecimentos, conteúdos, nem formar é ação pela qual um sujeito criador dá forma, estilo ou alma um corpo indeciso e acomodado. Não há docência sem discência, as duas se explicam e seus sujeitos, apesar das diferenças que os conotam, não se reduzem à condição de objeto um do outro (FREIRE, 2011, p. 25).

Freire (2014) defende a posição do professor como facilitador do processo ensinoaprendizagem, e valoriza a experiência, a observação da realidade e o diálogo entre os participantes deste processo, em uma relação horizontal, mediatizada pela realidade concreta, numa perspectiva pautada na ética, no amor, esperança, confiança e fé.

Quanto ao educando, as experiências já vividas pelo sujeito são próprias de sua história, sujeito criador da cultura e criador de sua história. Assim, o sujeito educando é 
comprometido com sua historicidade (FREIRE, 2014). Desse modo, os pensamentos de Freire se contrapõem à educação do tipo bancária, segundo a qual os educandos são tábulas rasas de conhecimento, e que precisam ser preenchidas por aqueles que julgam ser detentores de um saber mais. A prática docente deve ser construída, portanto, exercitando uma escuta e um olhar sensível.

[...] não é falando aos outros, de cima para baixo, sobretudo como se fôssemos os portadores da verdade a ser transmitida aos demais, que aprendemos a escutar, mas é escutando que aprendemos a falar com eles. Somente quem escuta paciente e criticamente o outro, fala com ele, mesmo que, em certas condições, precise falar a ele (FREIRE, 2011, p. 111)

Neste contexto, a obra Pedagogia do oprimido, ao referir-se à ação dialógica, afirma que: "Não há palavra verdadeira que não seja práxis. Daí que dizer a palavra verdadeira seja transformar o mundo" (FREIRE, 2020). E aponta o encontro que se estabelece na relação do homem a partir do diálogo, quando diz: "O diálogo é este encontro dos homens, mediatizados pelo mundo, para pronunciá-lo, não se esgotando, portanto na relação eu-tu" (FREIRE, 2020).

Santos et al. (2017) apontam que embora o arcabouço teórico de Paulo Freire seja datado anterior ao desenvolvimento da inclusão escolar brasileira, o autor marca na contemporaneidade uma consonância com o real conceito de inclusão, a partir de uma educação dialógica, pois as ideias freireanas defendem uma educação para todos, sem restrições, preconceitos ou discriminação.

Assim sendo, retomando a Pedagogia do Oprimido, o autor revela as características da teoria da ação dialógica, descrevendo a co-laboração, a união, a organização e a síntese cultural como pontos cruciais para a ação pedagógica. De modo a descrever cada característica, apresentam-se as concepções de Freire (2020) na obra:

- Co-laboração como processo dialógico da ação, em que os sujeitos se encontram para transformação do mundo. O diálogo não tem a função de impor, manejar ou domesticar, e sim traçar uma consciência clara do que se quer, dos objetivos pelos quais se comprometeu.

- Em relação aos aspectos da união, o autor defende a união para a libertação, descrevendo a "cultura do silêncio" que se gera na estrutura opressora, dentro da qual condiciona e impõe uma experiência de "quase-coisas". É com a união que se descobrem, em suas particularidades, a partir de ação cultural, problematizando em si mesmos os seus enfrentamentos com o mundo.

- O próximo ponto é a organização, e na teoria da ação dialógica, a organização, implicando na autoridade, não pode ser autoritária, implicando liberdade, não pode ser 
licenciosa. Mas se estabelece como um momento altamente pedagógico, em que a liderança, aqui referenciando o professor, junto ao estudante, fazem juntos, visa a transformação da realidade que os mediatiza.

- Por fim, a última característica: a síntese cultural, sendo esta a modalidade de ação com que, culturalmente, se fará da própria cultura, enquanto mantenedora das estruturas em que se forma, apresentando-se assim como ação histórica, e instrumento de superação da própria cultura alienada e alienante.

Neste contexto, o autor revela que assim como o opressor para oprimir necessita de uma teoria da ação opressora. Os oprimidos, para se libertarem, igualmente precisam de uma teoria de sua ação (FREIRE, 2020). Assim, retomamos a história de opressão que pessoas com deficiências vivenciaram, como afirma Oyan (2019), as escolas reproduziram os interesses das classes dominantes, separando os que aprendiam dos que não aprendiam. As escolas não assumiam a responsabilidade social de formar todos os cidadãos, mas somente aqueles que se interessavam e que tinham a atenção da família. Para um governo opressor, segundo o autor, um povo sem informação, sem recursos, sem estudo, é um povo fácil de governar, de comandar.

Oyan (2019) afirma que é importante reconhecer que a Pedagogia do Oprimido, escrita há décadas, é tão atual, necessária e, reconhecidamente, verdadeira, porque propõe uma reflexão sobre a metodologia e as teorias pedagógicas que embasam a prática opressora, mobilizando a escola e os seus segmentos para a reformulação e a construção de uma educação para a autonomia, para a liberdade.

Nesse âmbito, Freire (2011) tece algumas reflexões sobre o ato de ensinar e as exigências que esta prática impõe. Inicia seu pensamento relacionando o ensino à pesquisa e afirma que "[...] não há ensino sem pesquisa e pesquisa sem ensino" (FREIRE, 2011, p. 30). Assim, o educador ensina, porque busca, porque indaga, porque se indaga. Pesquisa para averiguar, constatar algo, intervir e educa se educando. $\mathrm{O}$ ato de ensinar exige também respeito ao conhecimento do educando e propõe que seja prática docente estabelecer uma intimidade entre os saberes curriculares e a experiência social que os discentes possuem como indivíduos.

É neste exercício constante de resistência, de pesquisa, de construção permanente, que a Pedagogia do Oprimido se apresenta de forma atual e nos mobiliza à libertação. Somos instigados ao posicionamento em favor do oprimido, por uma sociedade mais justa, mais digna, mais democrática e por uma Educação que construa novas possibilidades educativas, a 
partir da desalienação e do comprometimento com uma orientação preocupada em promover a emancipação da humanidade (HÖELZ, 2019). Diante de tais fatos, evidencia-se que a educação dialógica de Paulo Freire, política e libertadora, propõe, sem qualquer forma de discriminação, contemplando a democracia, a autonomia, a solidariedade, a ética, a adversidade e a esperança, perspectivas concretas de inclusão.

\section{Considerações finais}

Tendo em vista a construção de intervenções na educação especial de modo colaborativo, ainda se tem diversos obstáculos e inúmeros caminhos a serem trilhados. No entanto, a reflexão realizada tomando como base a obra de Paulo Freire, no debate para se encontrar caminhos para a concretização do sonho possível: uma educação libertadora, que construa com o sujeito a verdadeira inclusão, traz um alento e aponta o caminho, por demonstrar a importância da formação permanente do docente, no intuito de alcançar o desenvolvimento de competências e habilidades para subsidiar estratégias de ensino e aprendizagem, contribuindo assim para a construção de outro modo de vida mais justo na Educação Especial.

Apesar de ao longo da história o termo "deficiência" ainda estabelecer vários préconceitos, paradigmas, pensamentos "cristalizados", crenças que limitam a sociedade e a política a acreditarem que é difícil superar aquilo que já está posto como verdade: “a deficiência é limitante!", a ousadia deste tempo é continuar descontruindo, questionando, indagando e intervindo, para que a pessoa com deficiência deixe de viver uma condição de opressão e construa a liberdade a partir da educação.

Mudar é difícil, mas é possível, e para que se torne real, a ação-político-pedagógica precisa ser programada entre docente e discente, não importando qual o projeto que queremos ou precisamos desenvolver. Desse modo, coadunando com a obra Freireana, acredita-se que o êxito dos educadores e educandos está centralmente na certeza que jamais os abandona, de que é possível mudar, de que é preciso mudar, de que preservar situações concretas de miséria é uma imoralidade.

A partir da reflexão realizada conclui-se que é necessário que nos deixemos tomar pelo desejo de não desistir, de permanecer com a nossa aposta, lutando por uma educação especial pública, gratuita e de qualidade, acreditando que é possível a construção de novos modos de vida mais justos, igualitários, solidários, com respeito às diversas culturas e saberes. 


\section{REFERÊNCIAS}

ABREU, J. Para além da pedagogia do oprimido. In: $\mathbf{5 0}$ olhares sobre os 50 anos da pedagogia do oprimido. São Paulo: Instituto Paulo Freire, 2019. Disponível em:

https://www.cairu.br/arquivos/biblioteca/E-book_50_Olhares.pdf. Acesso em: 13 jul. 2020.

BARRETO, V. Paulo Freire para Educadores. São Paulo: Editora Arte e Ciência, 1998.

BRASIL. Lei n. 13.146, de 06 de julho de 2015. Institui a Lei Brasileira de Inclusão da Pessoa com Deficiência (Estatuto da Pessoa com Deficiência). Brasília, 2015. Disponível em:http://www.planalto.gov.br/ccivil_03/_ato2015-2018/2015/lei/113146.htm. Acesso em: 13 jul. 2020.

BRITO, C. G. S.; SILVA, N. C.; MONTENEGRO, L. Metodologia de Paulo Freire no desenvolvimento da educação permanente do enfermeiro intensivista. Rev. Enfermagem, v. 16, n. 03, 2012. Disponível em:

http://periodicos.pucminas.br/index.php/enfermagemrevista/article/view/21100. Acesso em: 10 jul. 2020.

CORRÊA, A. M. C. Pedagogia do oprimido, tantos anos depois. In: 50 olhares sobre os 50 anos da pedagogia do oprimido. São Paulo: Instituto Paulo Freire, 2019. Disponível em: https://www.cairu.br/arquivos/biblioteca/E-book_50_Olhares.pdf. Acesso em: 13 jul. 2020.

\section{DECLARAÇÃO DE SALAMANCA, Conferência Mundial sobre necessidades educacionais especiais. 1994}

FREIRE, P. Carta sobre Educação Permanente e a Cidade Educativa. Acervo do Centro de Referência Paulo Freire. São Paulo: Instituto Paulo Freire, nov. 1992.

FREIRE, P. Conscientização: teoria e prática da libertação: uma introdução ao pensamento de Paulo Freire. São Paulo: Cortez \& Moraes, 1979.

FREIRE, P. Pedagogia da Autonomia: Saberes Necessários à Prática Educativa. São Paulo: Paz e Terra. 2011.

FREIRE, P. Pedagogia da indignação: cartas pedagógicas e outros manuscritos. São Paulo: Paz e Terra, 2014.

FREIRE, P. Pedagogia do Oprimido. 75. ed. Rio de Janeiro: Paz e Terra, 2020

GADOTTI, M. et al. (org.). Paulo Freire: Uma biobibliografia. São Paulo: Instituto Paulo Freire, Editora Cortez, 1996.

HÖELZ, J. S. Ontem e hoje: um grito freiriano por liberdade. In: 50 olhares sobre os 50 anos da pedagogia do oprimido. São Paulo: Instituto Paulo Freire, 2019. Disponível em: https://www.cairu.br/arquivos/biblioteca/E-book_50_Olhares.pdf. Acesso em: 13 jul. 2020.

KASSAR. M. C. M. Educação especial na perspectiva da educação inclusiva: desafios da implantação de uma política nacional. Educar em Revista, Curitiba, n. 41, p. 61-79, jul./set. 2011. 
MARQUES, S. M. Pensar e agir na inclusão de crianças com necessidades educacionais especiais decorrente de uma deficiência, a partir de referenciais freirianos: rupturas e mutações culturais na escola brasileira. 2017. Tese (Doutorado) - Universidade de São Paulo, Universidade de Lumière Lyon 2, São Paulo, 2007.

MOURA, M. E. Pedagogia da palavra. In: 50 olhares sobre os 50 anos da pedagogia do oprimido. São Paulo: Instituto Paulo Freire, 2019. Disponível em:

https://www.cairu.br/arquivos/biblioteca/E-book_50_Olhares.pdf. Acesso em: 13 jul. 2020.

OYAN, E. M. O dia a dia da pedagogia do oprimido. In: 50 olhares sobre os 50 anos da pedagogia do oprimido. São Paulo: Instituto Paulo Freire, 2019. Disponível em: https://www.cairu.br/arquivos/biblioteca/E-book_50_Olhares.pdf. Acesso em: 13 jul. 2020.

PLETSCH, M. D. O que há de especial na educação especial brasileira? Momento - Diálogos em Educação, v. 29, n. 1, p. 57-70, jul. 2020. ISSN 2316-3100. DOI:

https://doi.org/10.14295/momento.v29i1.9357

POLO, A. O que esperar da escola e do professor de hoje. In: 50 olhares sobre os 50 anos da pedagogia do oprimido. São Paulo: Instituto Paulo Freire, 2019. Disponível em: https://www.cairu.br/arquivos/biblioteca/E-book_50_Olhares.pdf. Acesso em: 13 jul. 2020.

PORTUGUÊS, C. P. Na trilha da busca pela humanização. In: 50 olhares sobre os 50 anos da pedagogia do oprimido. São Paulo: Instituto Paulo Freire, 2019. Disponível em: https://www.cairu.br/arquivos/biblioteca/E-book_50_Olhares.pdf. Acesso em: 13 jul. 2020.

PURCARI, C. Pedagogia que liberta mediante a do-discência. In: 50 olhares sobre os 50 anos da pedagogia do oprimido. São Paulo: Instituto Paulo Freire, 2019. Disponível em: https://www.cairu.br/arquivos/biblioteca/E-book_50_Olhares.pdf. Acesso em: 13 jul. 2020.

REIS, P. J. F. M. Paulo Freire: análise de uma história de vida. 2012. Dissertação (Mestrado em Letras) - Universidade Federal de São João Del Rei, São João Del Rei, 2012.

SANTOS, J. H. et al. Pensar educação inclusiva em uma perspectiva freiriana. Ciências humanas e sociais, Alagoas, v. 4, n.2, p. 129-140, nov. 2017.

SANTOS, S. C. P. Educação permanente com vistas à integralidade do cuidado na rede de saúde mental. 2015. Dissertação (Mestrado em Enfermagem) - Universidade Federal Fluminense, Niterói, 2015.

UNESCO. Declaração Mundial de Educação para todos. Plano de ação para satisfazer as necessidades básicas de aprendizagem. Tailândia, 1990.

VITORINO, D. C. Entre Freire e Fanon: um diálogo transatlântico sobre a opressão. In: 50 olhares sobre os 50 anos da pedagogia do oprimido. São Paulo: Instituto Paulo Freire, 2019. Disponível em: https://www.cairu.br/arquivos/biblioteca/E-book_50_Olhares.pdf. Acesso em: 13 jul. 2020. 


\section{Como referenciar este artigo}

SANTOS, S. C. P.; VALENTE, G. S. C.; CORTEZ, E. A.; ASSAD, S. G. B.; VOGAS, R. S. Reflexão teórica sobre as contribuições da obra de Paulo Freire para a educação especial. Revista Ibero-Americana de Estudos em Educação, Araraquara, v. 16, n. 4, p. 2741-2759, out./dez. 2021. e-ISSN: 1982-5587. DOI: https://doi.org/10.21723/riaee.v16i4.14493

Submetido em: 13/07/2021

Revisões requeridas em: 16/08/2021

Aprovado em: 15/09/2021

Publicado em: 21/10/2021 